Development and Psychopathology, 12 (2000), 83-90

Copyright (C) 2000 Cambridge University Press

Printed in the United States of America

\title{
High “intelligence," low "IQ"? Speed of processing and measured IQ in children with autism
}

\author{
KRISTINA SCHEUFFGEN,${ }^{a}$ FRANCESCA HAPPÉ, ${ }^{b}$ MIKE ANDERSON, ${ }^{c}$ AND \\ $\mathrm{UTA} \mathrm{FRITH}^{a}$ \\ ${ }^{a}$ Institute of Cognitive Neuroscience and Department of Psychology, University College \\ London; ${ }^{b}$ Social, Genetic and Developmental Psychiatry Research Centre, Institute of \\ Psychiatry, London; and ${ }^{c}$ University of Western Australia, Nedlands
}

\begin{abstract}
The uneven profile of performance on standard assessments of intelligence and the high incidence of savant skills have prompted interest in the nature of intelligence in autism. The present paper reports the first group study of speed of processing in children with autism (IQ $1 S D$ below average) using an inspection time task. The children with autism showed inspection times as fast as an age-matched group of young normally developing children (IQ 1 $S D$ above average). They were also significantly faster than mentally handicapped children without autism of the same age, even when these groups were pairwise matched on Wechsler IQ. To the extent that IT tasks tap individual differences in basic processing efficiency, children with autism in this study appear to have preserved information processing capacity despite poor measured IQ. These findings have implications for the role of general and specific cognitive systems in knowledge and skill acquisition: far from showing that children with autism are unimpaired, we suggest that our data may demonstrate the vital role of social insight in the development of manifest "intelligence."
\end{abstract}

\section{Intelligence in Autism}

Autism, a developmental disorder affecting social and communicative skills (APA, 1994), differs from most forms of mental handicap in showing a characteristic pattern of poor, intact, and even superior cognitive abilities

This work was conducted at the MRC Cognitive Psychology Unit and the Department of Psychology, University College London, and forms part of Kristina Scheuffgen's Ph.D. thesis, which was supported by an MRC studentship. We are grateful to staff and children at six special schools and two main stream schools in London, Doncaster, and Plymouth for their unstinting cooperation in this project.

Address correspondence and reprint requests to: Uta Frith, UCL Institute of Cognitive Neuroscience, Alexandra House, 17 Queen Square, London WC1N 3AR, UK; E-mail: u.frith@ucl.ac.uk.
(Frith, 1989). Children and adults with autism, $75 \%$ of whom are mentally retarded, are consistently found to show prominent peaks and troughs on standard IQ assessments (e.g., Harris, Handleman, \& Burton, 1990; McDonald, Mundy, Kasari, \& Sigman, 1989; see Lincoln, Allen, \& Kilman, 1995, for review). Selective impairment on certain subtests (e.g., comprehension; Asarnow, Tanguay, Bott, \& Freeman, 1987) and superior performance on others (e.g., block design; Shah \& Frith, 1993) are commonly found (see Happé, 1994, for review). A verbal-performance discrepancy does not appear to describe the spiky IQ profile in autism (Siegel, Minshew, \& Goldstein, 1996): performance on picture arrangement (performance scale) is often poor, while digit span (verbal scale) is good. Certainly, autism seems to flout the premise of standard IQ tests, which include a set of heterogeneous 
subtests in order to extract the factor common to success across these tasks (general intelligence, or $g$; Spearman, 1904).

Autism also challenges notions of general intelligence by the frequent presentation of savant skills: areas of surprising talent in otherwise low-functioning individuals (O'Connor \& Hermelin, 1983). Savant abilities are perhaps 10 times more common in autism than in other forms of mental handicap, with an estimated incidence of 1 in 10 for the bestknown skills such as music, drawing, mnemonism, and calendar calculation (Rimland $\&$ Hill, 1984). The incidence in autism of some sort of skill out of line with general development (e.g., jigsaw construction, hyperlexia, memory for routes) is probably higher still.

It may be these islets of ability, along with the uneven profile of skills, which have led to the impression of good or superior intelligence in even apparently retarded children with autism. Thus, in the first report of autism, Kanner (1943) concluded that "The astounding vocabulary of the speaking children, the excellent memory .... and the precise recollection of complex patterns and sequences, bespeak good intelligence." Despite the impression that standard psychometric assessments fail to capture hidden intellectual strengths (most children with autism fall in the retarded range), performance on such assessments has proven stable over time (Lockyer \& Rutter, 1970; Lord \& Schopler, 1989; Freeman, Ritvo, Needleman, \& Yokota, 1985) and predictive of later achievement (Venter, Lord, \& Schopler, 1992; Gillberg \& Steffenburg, 1987). While these findings suggest that IQ measures are reliable in autism, they are no proof of validity: such measures may consistently underestimate intellectual potential. It is clear that many of the commonly used intelligence assessments involve both pragmatic and communicative elements, which cause difficulties for individuals with autism. These extraneous task demands may explain some of the peaks and troughs in performance; for example, deficits in understanding experimenter's intention may underlie poor performance on the comprehension subtest (Happé, 1994). In addition, a number of at- tested social-emotional, attentional, or executive deficits may adversely affect test-taking ability when pragmatic task demands are high.

These issues have rarely been explored within a conceptual model of intelligence. In this paper we adopt one such model and attempt to identify and test its predictions visà-vis autism.

\section{A Model of Intelligence}

Anderson's (1992) model of the minimal cognitive architecture is an attempt to disentangle modular processing from central processing, knowledge acquisition from intelligence, and development from maturation. Intelligence is viewed as an innate capacity that is determined by the speed of a basic processing mechanism (BPM). Speed of processing is hypothesized to be stable throughout development, constituting the innate component of individual differences, reflected in the concept of $g$ (Spearman, 1904). Modules (Fodor, 1983) for functions such as phonology, syntax, or theory of mind form another component in Anderson's model. The functioning of these modules is conceptualized as independent of the BPM. Good language abilities in otherwise mentally handicapped individuals may be taken as evidence of the functioning of a preserved module, spared by brain damage that affects predominantly the efficiency of the BPM. Anderson's model has been used to explain patterns of cognitive functioning in experimental case studies of special abilities, such as music (Sloboda, Hermelin, \& O'Connor, 1985), language (Smith \& Tsimpli, 1995), and mathematical skill (Anderson, O'Connor, \& Hermelin, in press).

Standard psychometric intelligence assessments confound the contribution of modular and central (BPM-dependent) processes. The speed of the BPM determines rate of knowledge acquisition and complexity of knowledge representations. While modular inputs are also fed to the central processes responsible for knowledge representation, these inputs are evolutionary invariant and thus do not add to individual variation in IQ test scores. However, failure of a module can result in striking 
patterns of cognitive breakdown that will influence intelligence test scores. In the case of such a modular impairment, central processes will not receive normal input, and consequently certain knowledge representations may be abnormal or absent. This may then show in a spiky IQ profile, where performance on subtests may be differentially affected. One simple, though daring, hypothesis is that individuals with autism, bar all but the lowest functioning, have impairments in one or more modular systems (notably theory of mind; Leslie \& Thaiss, 1992) but are unimpaired in BPM.

Anderson's model of intelligence is designed to accommodate the phenomena associated with intelligence and specific abilities, but the more general hypothesis that speed of information processing may be the basis of $g$ is widely held (Eysenck, 1986; Jensen, 1982, 1987; Nettelbeck, 1987; Vernon, 1983). Support for this hypothesis comes from, principally, the correlation between measures of speed of processing and intelligence. It has been argued that inspection time (IT) tasks provide the best single index of speed of processing (Anderson, 1986, 1992; Deary \& Stough, 1996).

\section{Assessing Speed of Information Processing}

The IT task requires a subject to make a very simple perceptual discrimination. Typically, the stimulus comprises two vertical line segments differing in length by a substantial amount (around 1 degree), proceeded by a masking stimulus designed to interrupt stimulus processing. The task is simply to indicate which is the longer line, and subjects can take as long as they wish to make a response; hence, IT, as opposed to RT (reaction time), is not contaminated by extraneous factors in motor programming. The interval between the onset of the stimulus and its termination by the mask-stimulus onset asynchrony (SOA) - is systematically varied using an adaptive procedure that provides a point estimate of the psychometric function relating discrimination accuracy to SOA. Inspection time is calculated as the SOA a subject requires for a given level of accuracy.
The data show that individuals with lower IQs tend to require longer stimulus exposures than individuals with higher IQs to maintain the same level of accuracy. Numerous studies have reported significant correlations between IT and IQ as measured by, for example, the Wechsler scales (e.g., Nettelbeck \& Lally, 1976; Nettelbeck, Hirons, \& Wilson, 1984; Nettelbeck, 1982; Lally \& Nettelbeck, 1980; Brand \& Deary, 1982; Brand, 1980). Some have questioned the interpretation that these correlations are caused by the relationship between speed of processing and intelligence (Howe, 1988; Mackintosh, 1986) and argue that they are based on artifactual effects such as better task comprehension or motivation in higher IQ subjects. Other authors have argued against this explanation, citing evidence that strategy use, for example, actually reduces the relation between IT and IQ (Deary \& Stough, 1996; Nettelbeck, 1990; Sternberg, 1988).

In a review of 29 theses and published articles, Nettelbeck (1987) found a reliable relationship between IT and IQ. His considered estimate of the strength of the correlation across the full range of IQ is -.5 . Kranzler and Jensen (1989) conducted a meta-analysis of 25 studies that included measures of general intelligence. Although a negative relationship between IT and IQ was always obtained, the $95 \%$ confidence interval for each correlation contained zero. Kranzler and Jensen (1989) then corrected the coefficients for the effects of sampling error, attenuation and range restriction, arriving at a best estimate of -.54 for the correlation between IT and IQ in adults.

The present paper reports a first study of inspection time in autism. We hypothesize that although measured intelligence in individuals with autism is usually in the retarded range, this is not necessarily due to slow information processing speed but rather could be due to specific impairments in social communication. The prediction for the present study, then, is that for individuals with autism whose measured IQ is below the normal range, IT will be equal to that of normally developing individuals with significantly higher measured IQ. Our participants, who had measured IQs on average in the 80s (1 SD 
Table 1. Participant characteristics

\begin{tabular}{lccrrr}
\hline \hline Group & $N$ & (Years: Months) & \multicolumn{1}{c}{ VIQ } & \multicolumn{1}{c}{ PIQ } & \multicolumn{1}{c}{ FIQ } \\
\hline Autism & 18 & $11: 5(3: 5)$ & $81.8(24.5)$ & $86.8(20.4)$ & $82.8(20.5)$ \\
MLD & 21 & $11: 3(1: 1)$ & $65.3(8: 5)$ & $67.1(11.0)$ & $62.4(9.2)$ \\
Normal & $29^{a}$ & $11: 7(2: 9)$ & $117.3(16.6)$ & $114.9(16.9)$ & $118.1(16.8)$ \\
\hline \hline
\end{tabular}

Note: The values are mean $(S D)$.

${ }^{a}$ IQ data available for 26 subjects.

below normal average), were relatively high functioning when compared to the autism population as a whole but seemed particularly suitable for a first exploration of this question, since good task understanding and cooperation could be readily obtained.

\section{Method}

\section{Participants}

A group of 18 subjects with autism, a group of 21 subjects with moderate learning difficulties (MLD), ${ }^{1}$ and a group of 29 normally developing subjects took part in this study. Participant characteristics are shown in Table 1. Individuals in the autism group (17 male, 1 female) came from three schools for children with autism. Fifteen had received an independent diagnosis of autism and 3 had received an independent diagnosis of Asperger syndrome according to the clinical criteria of DSM-IV (APA, 1994). The autism and Asperger subjects did not differ in IQ (81 vs. 83), but the Asperger syndrome individuals were somewhat older (15-16 years vs. mean 10.6 years). Individuals with MLD (14 male, 7 female) came from three special schools and were of mixed and unknown etiologies. The normally developing group (22 male, $7 \mathrm{fe}$ male) were 7- to 16-year-olds who were range matched for age with the children with autism. The selection of an above average IQ group allowed a particularly stringent test of

1. In the United Kingdom, the term moderate learning difficulties is used for individuals with generally low ability or low developmental level for their chronological age (i.e., synonymously with mental handicap or mental retardation). the hypothesis of unimpaired speed of processing in autism. IQ was assessed using the Wechsler Intelligence Scale for Children (third edition; Wechsler, 1992). Two subtests from the verbal scale (vocabulary, similarities) and two subtests from the performance scale (picture completion, block design) were given to all participants, and verbal (VIQ), performance (PIQ), and full-scale IQ (FIQ) were prorated. IQ scores were not available for 3 of the 29 normally developing children. Where available, data from a full WISC-III assessment were used (14 cases from the autism group). The typical profile (Happé, 1994) of peak performance on block design was found in 9 of these 14 children with autism, and the typical dip on the comprehension subtest characterized 12 of the 14 .

\section{Procedure}

The IT task was presented in the form of a computer game specially devised for children. The stimulus shown was a line-drawn alien with two antennae which were either the same or different lengths. Four variations (both antennae short, both antennae long, left antenna longer, right antenna longer) were randomly presented. The subject's task was to make a two-choice-same or different length antennae-discrimination. Stimulus duration was controlled by a mask. Subjects were warned that the alien would appear for a very brief period before hiding behind a bush (the backward mask). After presentation of a stimulus the subject had to press one of two buttons on a simple purpose-made box to indicate same or different length antennae. The button for "Same" was on the left, and a picture of an alien with two equally long antennae was dis- 
played on the left of the computer screen. The same arrangement applied to the button for "Different" on the right. Each correct response was followed by a beep. After each button press the subject pressed the space bar to initiate the next stimulus.

Stimulus exposure duration was controlled by varying the SOA of the stimulus and a backward mask, using a PEST procedure (Taylor \& Creelman, 1967) designed to estimate $70 \%$ accuracy of responding. The PEST algorithm decides whether a given SOA results in accuracy greater or less than $70 \%$. If so, the SOA is increased or decreased as appropriate by a given step size. This step size is halved for every change of direction in the performance staircase (increasing SOA to decreasing SOA or vice versa), and in this way the PEST procedure homes in on the SOA required for the desired level of accuracy. The initial exposure duration used by the PEST procedure was $568 \mathrm{~ms}$ (40 VDU screen frames), the initial step size was $114 \mathrm{~ms}$ (8 frames), and the final step size was $14.2 \mathrm{~ms}$ (1 frame), which is the shortest SOA possible. The SOAs of the last four turns or reversals in the performance staircase were used to calculate a subject's IT. A trial consisted of four blocks, each of 25 stimulus presentations.

The IT program was run on a Toshiba laptop computer, with stimuli displayed on a 12in. VGA monochrome monitor (brightness held constant across test sessions). A response box with two differently colored buttons was held by the subject, with right and left thumb or index finger operating the right and left buttons, respectively.

All subjects were seen individually in a quiet place at school. The subjects were first introduced to the task during a practice session with feedback. All subjects were taken through the IT task twice, the testing session lasting approximately $0.5 \mathrm{hr}$. We did this to obtain optimal performance in the clinical groups and to ameliorate possible effects of poor comprehension of instructions, attention, or motivation. Practice effects were observed over the first four blocks, in particular in the coordination of attention (i.e., indicating readiness by pressing the space bar while at the same time watching the screen) and the
Table 2. IT scores (ms)

\begin{tabular}{llcc}
\hline \hline Group & $N$ & \multicolumn{2}{c}{ Inspection Times } \\
\hline Autism & 18 & 40.3 & $(8.5)$ \\
MLD & 21 & $59.4^{a}(24.4)$ \\
Normal & 29 & $43.8 \quad(9.9)$ \\
\hline \hline
\end{tabular}

Note: The values are mean $(S D)$.

${ }^{a}$ The MLD group was significantly slower than the young normally developing group and the autism group $(p<.05)$.

understanding that responses were untimed (i.e., no need to race to respond at the cost of impulsive errors). IT scores (milliseconds) reported here are therefore taken from the four blocks of the second trial.

\section{Results}

Table 2 shows mean inspection times and standard deviations for each of the three groups of subjects. The 15 subjects diagnosed with autism did not differ in their IT scores from the three subjects diagnosed with Asperger syndrome (mean 43 vs. $40 \mathrm{~ms}$ ) and their results were therefore combined.

A one-way ANOVA showed a significant group effect, $F(2,67)=8.83, p=.0004$. Follow-up Tukey tests showed that the MLD group had significantly $(p<.05)$ longer inspection times than did participants in the autism or normally developing groups, who did not differ from each other.

\section{Comparison of IT in IQ-matched subgroups}

As can be seen in Table 1, the MLD group was of lower measured IQ than the autism group. To ensure that this difference could not account for the difference in IT performance, a comparison of FIQ-matched pairs of subjects was performed (where age did not differ significantly). As Table 3 shows, even when IQ-matched, the subjects with autism performed significantly better on the IT task than did the MLD group $(t=2.54, d f=18, p=.020)$.

\section{Discussion}

Inspection times in the autism group were as fast as those of normally developing children, despite significantly poorer measured IQ. By 
Table 3. IT scores (ms) for WISC FIQ pairwise

matched subgroups

\begin{tabular}{lcccc}
\hline \hline Group & $N$ & $\begin{array}{c}\text { Age } \\
\text { (Years : Months) }\end{array}$ & FIQ & IT Score \\
\hline Autism & 10 & $12: 1(3: 7)$ & $68.0(8.2)$ & $42.5^{a}(8.8)$ \\
MLD & 10 & $10: 11(0: 4)$ & $67.4(7.2)$ & $58.4(17.7)$ \\
\hline \hline
\end{tabular}

Note: The values are mean $(S D)$.

${ }^{a}$ The IT group difference was $t=2.54, d f=18, p=.020$.

contrast, inspection times for the group with learning difficulties were significantly longer than those of the normally developing group and in line with their lower IQ test scores. The MLD group had substantially longer ITs than the autism group, despite similar IQs in subgroups compared (omitting all those individuals with autism whose IQ was above 76). These results support the notion of a general information processing deficit in the MLD group, and a specific deficit in the autism group which is independent of basic processing speed.

The relatively small sample sizes in this first study of IT in autism dictate caution in extrapolating the results to other groups. In particular, many children with autism have IQs considerably lower than the subjects tested here, and it is unclear whether IT performance would be comparably good in these individuals. Future research is needed to assess IT in lower functioning people with autism. In addition, the group with learning difficulties had received their diagnosis and school placement on the basis of low measured IQ and resultant academic difficulties and was thus a heterogeneous group. It remains to be seen whether the present results apply to developmentally delayed groups of known etiology.

What does unimpaired IT performance imply for intelligence in autism? The necessary speed of information processing required for learning and complex knowledge acquisition appears to be present, yet many children with autism fail to acquire the information and skills tapped by IQ tests. Why? A number of authors have suggested cognitive deficits in autism which might be thought to compromise test performance-for example, attentional deficits (Burack \& Enns, 1997; Town- send, Courchesne, \& Egaas, 1996), executive dysfunction (Russell, 1998), failure to integrate information (Frith, 1989; Waterhouse, Fine, \& Modahl, 1996). We add the suggestion that a failure to understand others' thoughts and feelings may affect measured intelligence both on-line and developmentally (Frith \& Happé, 1998).

Children with autism may fail to acquire the knowledge and skills of their peers due to a deficit in theory of mind. Theory of mind refers to the everyday ability to attribute mental states (e.g., beliefs and intentions) to self and others to explain and predict behavior (see Carruthers \& Smith, 1996). Children and adults with autism fail tests of this ability (see Baron-Cohen, Tager-Flusberg, \& Cohen, 1993), and this test performance relates strongly to everyday life social adaptation and communicative ability (Frith, Happé, \& Siddons, 1994). In addition to these on-line effects, Frith \& Happé (1998) have suggested that the ability to understand others' thoughts may serve a "gatekeeper" function for a number of other developmental competencies.

Failure to recognize the intentions of others, whether during deliberate pedagogy or in general goal-directed purposeful action, may have a dramatic impact on learning (Frith \& Happé, 1994). Recent research has, for example, highlighted the importance of theory of mind in the normal learning of the agreed words for things (Baldwin, 1993; Tomasello, 1992). At the same stage of development (around 18 months) the young normal child is able to imitate incomplete intended actions (Meltzoff, 1995), distinguishing them from accidental or robot movements. Learning by observation and imitation of peers and adults is a key element of normal skill acquisition (Hanna \& Meltzoff, 1993; Premack, 1995). 
The idea that people with autism miss out on socially transmitted skills and information, despite apparently intact information processing potential, fits well with Asperger's (1944; trans. Frith, 1991) original insights into the puzzle of autistic intelligence:

\section{References}

American Psychiatric Association. (1994). Diagnostic and statistical manual of mental disorders (4th ed.). Washington, DC: Author.

Anderson, M. (1986). Inspection time and IQ in young children. Personality and Individual Differences, 7, 677-686.

Anderson, M. (1992). Intelligence and development: A cognitive theory. Oxford: Blackwell.

Anderson, M., O'Connor, N., \& Hermelin, B. (in press). A specific calculating ability. Intelligence.

Asarnow, R. F., Tanguay, P. E., Bott, L., \& Freeman, B. J. (1987). Patterns of intellectual functioning in nonretarded autistic and schizophrenic children. Journal of Child Psychology and Psychiatry, 28, 273-280.

Baldwin, D. A. (1993). Early referential understanding: Infants' ability to recognize referential acts for what they are. Developmental Psychology, 29, 832-843.

Baron-Cohen, S., Tager-Flusberg, H., \& Cohen, D. J. (Eds.). (1993). Understanding other minds: Perspectives from autism. Oxford: Oxford University Press.

Brand, C. (1980). General intelligence and mental speed: Their relationship and development. In M. Friedman, J. P. Das, \& N. O'Connor (Eds.), Intelligence and learning. New York: Plenum.

Brand, C., \& Deary, I. J. (1982). Intelligence and inspection time. In H. J. Eysenck (Ed.), A model for intelligence. New York: Springer-Verlag.

Burack, J. A., \& Enns, J. T. (Eds.). (1997). Attention, development, and psychopathology. New York: Guilford Press.

Carruthers, P., \& Smith, P. K. (Eds.). (1996). Theories of theories of mind. Cambridge: Cambridge University Press

Deary, I., \& Stough, C. (1996). Intelligence and inspection time. American Psychologist, 15, 599-608.

Eysenck, H. J. (1988). The concept of "intelligence": Useful or useless? Intelligence, 12, 1-16.

Fodor, J. A. (1983). The modularity of mind. Cambridge, MA: MIT Press.

Freeman, B. J., Ritvo, E. R., Needleman, R., \& Yokota, A. (1983). The stability of cognitive and linguistic parameters in autism: A five-year prospective study. Journal of the American Academy of Child Psychiatry, 24, 459-464.

Frith, U. (1989). Autism: Explaining the enigma. Oxford: Basil Blackwell.

Frith, U. (1991). Autism and Asperger syndrome. Cambridge: Cambridge University Press.

Frith, U., \& Happé, F. (1994). Language and communication in the autistic disorders. Philosophical Transactions of the Royal Society, Series B, 346, 97-104.

Frith, U., \& Happé, F. (1998). Why specific developmental disorders are not specific: On-line and developmental effects in autism and dyslexia. Developmental Science, 1, 267-272.
[T]here is an inability to learn from adults in conventional ways. Instead, the autistic individual needs to create everything out of his own thought and experience. More often than not this results in defective performance, even in the more able autistic individuals. (p. 56)

Frith, U., Happé, F., \& Siddons, F. (1994). Autism and theory of mind in everyday life. Social Development, $3,108-124$.

Gillberg, C., \& Steffenburg, S. (1987). Outcome and prognostic factors in infantile autism and similar conditions: A population-based study of 46 cases followed through puberty. Journal of Autism and Developmental Disorders, 17, 273-287.

Hanna, E., \& Meltzoff, A. N. (1993). Peer imitation by toddlers in laboratory, home, and day-care contexts: Implications for social learning and memory. Developmental Psychology, 29, 701-710.

Happé, F. G. E. (1994). Wechsler IQ profile and theory of mind in autism: A research note. Journal of Child Psychology and Psychiatry, 35, 1461-1471.

Harris, S., Handleman, J. S., \& Burton, J. L. (1990). The Stanford Binet profiles of young children with autism. Special Services in the Schools, 6, 135-143.

Howe, M. J. (1988). Intelligence as an explanation. British Journal of Psychology, 79, 349-360.

Jensen, A. R. (1982). Reaction time and psychometric $g$. In Eysenck, H. J. (Ed.), A model for intelligence. Berlin: Springer-Verlag.

Jensen, A. R. (1987). Process differences and individual differences in some cognitive tasks. Intelligence, 11, 107-136.

Kanner, L. (1943). Autistic disturbances of affective contact. Nervous Child, 2, 217-250.

Kranzler, J. H., \& Jensen, A. R. (1989). Inspection time and intelligence: A meta-analysis. Intelligence, 13, 329-347.

Lally, M., \& Nettelbeck, T. (1980). Intelligence, inspection time and response strategy. American Journal of Mental Deficiency, 84, 553-560.

Leslie, A. M., \& Thaiss, L. (1992). Domain specificity in conceptual development: Evidence from autism. Cognition, 43, 225-251.

Lincoln, A. J., Allen, M. H., \& Kilman, A. (1995). The assessment and interpretation of intellectual abilities in people with autism. In Schopler, E., \& Mesibov, G. B. (Eds.), Learning and cognition in autism (pp. 89-117). New York: Plenum Press.

Lockyer, L., \& Rutter, M. (1970). A five to fifteen year follow-up study of infantile psychosis: IV. Patterns of cognitive ability. British Journal of Social and Clinical Psychology, 9, 152-163.

Lord, C., \& Schopler, E. (1989). Stability of assessment results of autistic and non-autistic language-impaired children from preschool years to early school age. Journal of Child Psychology and Psychiatry, 30, 575-590.

Mackintosh, N. J. (1986). The biology of intelligence? British Journal of Psychology, 77, 1-18.

McDonald, M. A., Mundy, P., Kasari, C., \& Sigman, M. (1989). Psychometric scatter in retarded, autistic pre- 
schoolers as measured by the Cattell. Journal of Child Psychology and Psychiatry, 30, 599-604.

Meltzoff, A. N. (1995). Understanding the intentions of others: Re-enactment of intended acts by 18-monthold children. Developmental Psychology, 31, 838850.

Nettelbeck, T. (1982). Inspection time: An index for intelligence? Quarterly Journal of Experimental Psychology, 34, 299-312.

Nettelbeck, T. (1987). Inspection time and intelligence. In P. A. Vernon (Ed.), Speed of information processing and intelligence. New York: Ablex.

Nettelbeck, T. (1990). Intelligence does exist: A rejoinder to M. J. A. Howe. The Psychologist: Bulletin of the British Psychological Society, 3, 494-497.

Nettelbeck, T., Hirons, A., \& Wilson, C. (1984). Mental retardation, inspection time, and central attentional impairment. American Journal of Mental Deficiency, 89, 91-98.

Nettelbeck, T., \& Lally, M. (1976). Inspection time and measured intelligence. British Journal of Psychology, 67, 17-22.

O'Connor, N., \& Hermelin, B. (1983). The role of general ability and specific talents in information processing. British Journal of Developmental Psychology, 1, 389-403.

Premack, D. (1995). On the control of human individual differences. In D. J. Lubinski \& R. V. Dawis, (Eds.), Assessing individual differences in human behavior: New concepts, methods, and findings (pp. 329-339). Palo Alto, CA: Davies-Black.

Rimland, B., \& Hill, A. L. (1984). Idiot savants. In J. Wortis (Ed.), Mental retardation and developmental disabilities (Vol. 13, pp. 155-169). New York: Plenum Press.

Russell, J. (1998). Autism as an executive disorder. Oxford: Oxford University Press.

Shah, A., \& Frith, U. (1993). Why do autistic individuals show superior performance on the Block Design task?
Journal of Child Psychology and Psychiatry, 34, 1351-1364

Siegel, D. J., Minshew, N. J., \& Goldstein, G. (1996) Wechsler IQ profiles in the diagnosis of high-functioning autism. Journal of Autism and Developmental Disorders, 26, 389-406.

Sloboda, J. A., Hermelin, B., \& O'Connor, N. (1985). An exceptional musical memory. Music Perception, 3, 155-170.

Smith, N., \& Tsimpli, I. (1995). The mind of a savant: Language learning and modularity. Oxford: Blackwell.

Spearman, C. (1904). "General intelligence" objectively determined and measured. American Journal of Psychology, 15, 201-293.

Sternberg, R. J. (1988). Explaining away intelligence: A reply to Howe. British Journal of Psychology, 79, 527-533.

Taylor, M. M., \& Creelman, C. D. (1967). PEST: Efficient estimates on probability functions. Journal of the Acoustical Society of America, 41, 782-787.

Tomasello, M. (1992). The social bases of language acquisition. Social Development, 1, 68-87.

Townsend, J., Courchesne, E., \& Egaas, B. (1996). Slowed orienting of covert visual-spatial attention in autism: Specific deficits associated with cerebellar and parietal abnormality. Development and Psychopathology, 8, 563-584.

Venter, A., Lord, C., \& Schopler, E. (1992). A follow-up study of high-functioning autistic children. Journal of Child Psychology and Psychiatry, 33, 489-507.

Vernon, P. A. (1983). Speed of information processing and intelligence. Intelligence, 7, 53-70.

Waterhouse, L., Fine, D., \& Modahl, C. (1996). Neurofunctional mechanisms in autism. Psychological Review, 103, 457-489.

Wechsler, D. (1992). Wechsler Intelligence Scale for Children (3rd ed.). New York: Psychological Corporation. 